\title{
Identifikasi Citra Batu Mulia dengan Menggunakan Metode Jaringan Saraf Tiruan Backpropagation
}

\author{
Meylda Kurnia Emylia Putri \\ Jurusan Teknik Informatika, Fakultas Bioindustri dan Telematika \\ Universitas Trilogi \\ Jakarta Selatan, Indonesia \\ e-mail: meyldakurniaemyliaputri@gmail.com \\ Diajukan: 6 Juni 2019; Direvisi: 10 Juli 2019; Diterima: 11 Juli 2019
}

\begin{abstract}
Abstrak
Batuan mulia (gemstone) merupakan salah satu kekayaan alam yang dapat dijadikan perhiasan dan koleksi. Terdapat beberapa jenis batuan seperti ruby, sapphire, zamrud, topaz, kecubung, dan kalimaya. Jenis batuan mulia tersebut dapat dikenali berdasarkan tekstur, motif, dan warnanya. Keberagaman atas jenis batuan mulia akan menjadi kendala bagi konsumen untuk mengidentifikasi bebatuan asli, palsu dan sintetis dikarenakan minimnya akan pengetahuan dan kemampuan individu dalam mengidentifikasi bebatuan mulia. Kemiripan Antara batuan mulia asli, sintetis, dan palsu menjadi suatu permasalahan dalam pemilihan batuan tersebut. Berdasarkan permasalahan yang telah dijabarkan maka dengan dibuatnya sistem basis jaringan saraf tiruan dapat mengidentifikasi dan mengenali batuan mulia, asli, palsu, atau sintetis dikarenakan jaringan saraf tiruan merupakan salah satu ilmu computer yang dapat mempelajari dan menirukan kerja otak manusia dibidang pengelompokan dan pengenalan pola. Untuk pengaplikasian tersebut, algoritma yang akan digunakan yaitu backpropagation dan hasil dari keakurasian adalah $85 \%$.
\end{abstract}

Kata kunci: Backpropagation, Jaringan Saraf Tiruan, Gemstone, Batu Mulia.

\begin{abstract}
Gemstone is one of the natural resources that can be used as jewelry and collections. There are several types of rocks such as ruby, sapphire, emerald, topaz, amethyst, and kalimaya. These precious rock types can be identified based on their texture, motif and color. The diversity of precious rock types will be an obstacle for consumers to identify genuine, fake and synthesized rocks due to the lack of individual knowledge and ability to identify noble rocks. Similarities between original precious stones, synthesis, and counterfeit are a problem in the selection of these rocks. Based on the problems that have been described, the artificial neural network base system can identify and recognize noble, original, false, or synthetic rocks because artificial neural networks are one of the computer sciences that can study and imitate the work of the human brain in the field of pattern recognition and grouping. For the application, the algorithm to be used is backpropagation and the result of accuracy is $85 \%$.
\end{abstract}

Keywords: Neural Network, Backpropagation, Gemstone.

\section{Pendahuluan}

Pemanfaatan kekayaan alam yang ada di dunia ini tidak akan ada habisnya, semua bisa dimanfaatkan baik dari golongan abiotik maupun biotik. Bahkan dari letusan gunung berapi dapat dimanfaatkan seperti abu vulkanik dari letusan gunung untuk menyuburkan tanaman, pasir-pasir untuk bahan material, dan isi dari perut gunung merapi hasil dari proses geologi melalui diferensiasi magma, metamorfosis dan sedimentasi yang menghasilkan batuan mulia (gemstone).

Hasil pembentukan batu tersebut maka adanya istilah batuan mulia yang dapat dikoleksi karena memiliki bentuk, motif dan texture yang indah sehingga dapat dikoleksi dan dijadikan perhiasan. Batu mulia adalah suatu mineral yang ketika dipoles dan disayat dapat digunakan untuk perhiasan [6]. Bebatuan mulia terdapat beberapa jenis seperti zamrud, ruby, sapphire, topaz, kecubung, dan kalimaya. Beberapa cara untuk mengenali atau mengidentifikasi jenis bebatuan mulia tersebut dengan mengingat tekstur, motif, dan warna. 
Karena keindahan dari batuan mulia maka banyak kemungkinan untuk memproduksi batuan mulia palsu, sintetis, maupun asli. Hal tersebut akan menjadi kendala bagi penggemar batuan mulia. Tetapi ada beberapa cara supaya mempermudah mengenali jenis bebatuan tersebut dengan mengimplementasikannya di dalam perangkat lunak lalu diidentifikasi jenis bebatuan tersebut. Dalam penelitian ini mengambil sample dari batu ruby sintetis dan ruby asli untuk mengidentifikasi batuan mulia. Maka dengan mengidentifikasi citra jenis batuan mulia dengan metode jaringan saraf tiruan backpropagation dapat mempermudah masyarakat untuk mengenal jenis bebatuan mulia.

Metode jaringan saraf tiruan yaitu salah satu cabang dari Artificial Intelligence (AI) atau kecerdasan buatan. Cara kerja jaringan saraf tiruan ini dilakukan dengan cara menirukan kerja otak makhluk hidup yaitu sel saraf atau neuron. Jaringan saraf tiruan memiliki kemampuan untuk memperoleh dan mempertahankan suatu pengetahuan (informasi berbasis) dan dapat didefinisikan sebagai satu set unit pengolahan, diwakili oleh neuron buatan, saling terkait oleh banyak interkoneksi (sinapsis buatan), di implementasikan oleh vektor dan matriks bobot sinaptik [7]. Pada metode ini memiliki dua algoritma yaitu backpropagation dan forward propagation. Dalam penelitian ini algoritma yang digunakan yaitu algoritma backpropagation. Algoritma backpropagation yaitu suatu algoritma jaringan saraf tiruan yang memiliki lapisan persepsi banyak, lapisan tersebut terdiri dari lapisan tersembunyi, lapisan input dan lapisan output. Prinsip kerja dari algoritma backpropagation ini harus menentukan apriori, beberapa variable dan parameter tambahan yang digunakan untuk tujuan tersebut.

\section{Metode Penelitian}

Metode yang digunakan pada penelitian ini yaitu meliputi lima proses, lima proses tersebut yaitu akuisisi citra batu, image preprocessing, segmentasi, ekstraksi citra, implementasi backpropagation, berikut diagram alur yang pada penelitian ini :

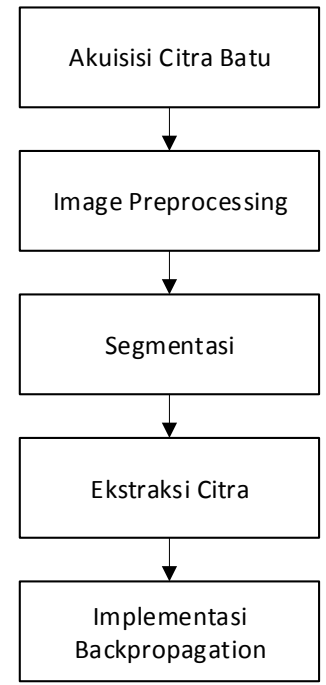

Gambar 1 . Flowchart Identifikasi Batu Mulia.

Berdasarkan diagram alur yang di atas terdapat beberapa tahap proses identifikasi batu, proses, berikut penjelasan dari diagram alur yang tertera pada Gambar 1:

\section{A. Akuisisi citra batu}

Mengambil beberapa sampel batuan mulia, dan mengumpulkan citra batuan mulia lalu disimpan file tersebut dengan format .jpg.

\section{B. Preprocessing}

Pada proses ini melakukan suatu pengambilan sampel pada batu mulia, ubah gambar menjadi 256x256 piksel. Lalu ubah warna citra batu menjadi RGB lalu dikonversi menjadi grayscale. Pada proses ini input gambar yang ingin diproses, berikut gambar yang di-input-kan dan telah diubah menjadi 256x256 piksel. 


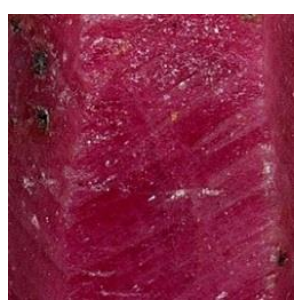

Gambar 2. Ruby.

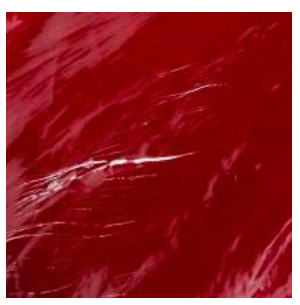

Gambar 3. Ruby Sintetis.

Setelah gambar diubah menjadi 256x256 piksel lalu proses selanjutnya yaitu mengubah gambar dari masing-masing objek dalam bentuk RGB (Red, Green, Blue). Berikut hasil dari masing-masing objek berbentuk RGB.
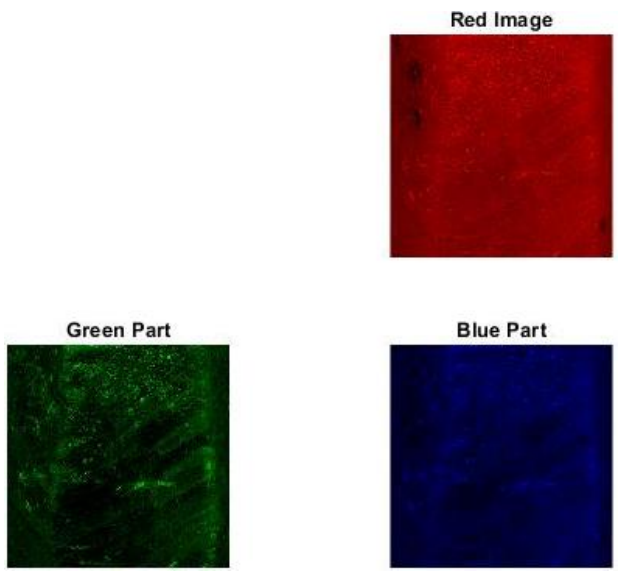

Gambar 4. Image Preprocessing RGB: Ruby.
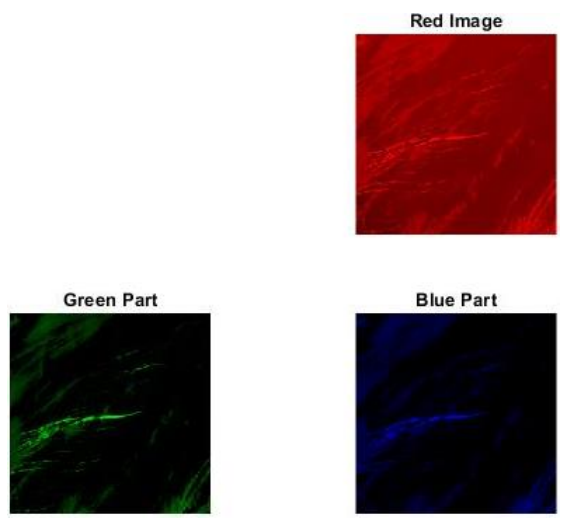

Gambar 5. Image Processing RGB: Ruby Sintetis.

C. Segmentasi

Pada tahap segmentasi citra dilakukan dengan menggunakan metode thresholding. Metode thresholding merupakan metode yang sederhana dan efektif untuk memisahkan objek dengan latar belakangnya. Metode thresholding dapat melakukan proses binary. Thresholding pada proses ini digunakan

Identifikasi Citra Batu Mulia dengan Menggunakan Metode Jaringan Saraf Tiruan Backpropagation (Meylda Kurnia Emylia Putri) 
untuk mengirik tekstur permukaan citra batu yang sudah di-input-kan, dan menentukan nilai intensitas tekstur citra batuan. Berikut gambar yang sudah melewati tahap thresholding.
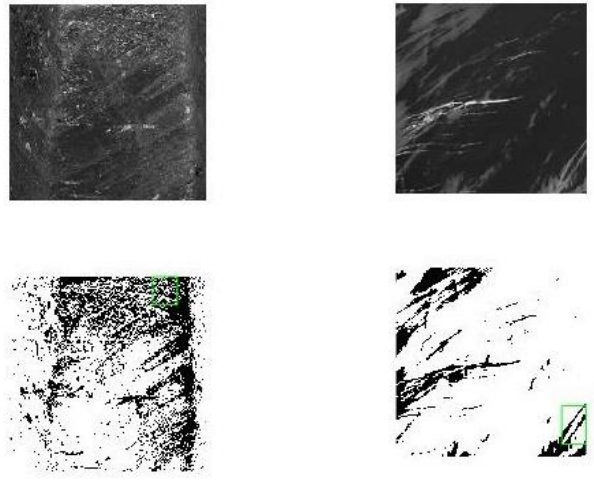

Gambar 6. Thresholding Ruby dan Ruby Sintetis.

\section{Ekstrasi Citra}

Citra batu yang sudah melewati proses segmentasi dengan metode thresholding lalu diubah menjadi sebuah matriks berukuran 256x256 yang berisikan bilangan-bilangan biner yang menggambarkan citra piksel pemetaan-bit dari sebuah gambar yang sudah diproses.

E. Identifikasi citra batuan menggunakan jaringan syaraf tiruan menggunakan algoritma backpropagasi.

Berikut metode untuk mengidentifikasi citra batuan mulia menggunakan algoritma backpropagasi

a. Inisialisasi bobot

Menentukan angka pembelajaran $(\alpha)$, lalu menentukan nilai toleransi error atau nilai ambang apabila menggunakan nilai ambang sebagai kondisi berhenti, atau set nilai minimal epoch.

b. Selama kondisi berhenti belum terpenuhi maka laksanakan tahap c sampai ke j

c. Untuk tiap pasangan pola pelatihan, lakukan tahap ke-d sampai ke-i

d. Pada langkah ke-d sampai ke f melakukan tahap feed forward: Tahap pertama yaitu setiap unit input $\mathrm{x}_{\mathrm{i}}$ dari unit ke-1 sampai unit ke-n pada lapisan input mengirimkan sinyal input ke semua unit yang ada di lapisan tersembunyi.

e. Setelah itu setiap unit di lapisan tersembunyi $\mathrm{z}_{\mathrm{j}}$ dari unit ke-1 sampai unit ke-p sinyal output lapisan tersembunyinya dihitung dengan menerapkan fungsi aktivasi terhadap penjumlahan sinyal-sinyal input berbobot $\mathrm{x}_{\mathrm{i}}$.

$$
z_{j}=f\left(V_{0 j}+\sum x i V_{i j}\right)_{i=1}^{n}
$$

f. Tiap unit di lapisan output $y_{k}$ dari unit ke-1 samapai unit ke-m dihitung sinyal outputnya dengan menggunakan fungsi aktivasi terhadap penjumlahan sinyal-sinyal input berbobot $z_{j}$ bagi lapisan ini:

$$
y_{k}=f\left(w_{0 k}+\sum z j w_{j k}\right)_{i=1}^{p}
$$

g. Untuk langkah ke-g sampai h melakukan pengecekan backpropagasi error, yaitu setiap unit output $y_{k}$ dari unit ke-1 sampai unit ke-m menerima pola target $t_{k}$ lalu informasi kesalahan lapisan output $\delta_{k}$ dihitung. $\delta_{k}$ dikirim ke lapisan di bawahnya dan digunakan untuk menghitung besar koreksi bobot dan bias antara lapisan tersembunyi dengan lapisan output :

$$
\begin{gathered}
\delta_{k}=\left(t_{k}-y_{k}\right) f^{\prime}\left(w_{0 k}+\sum z_{j} w_{j k}\right)_{j=1}^{p} \\
\Delta w_{j k}=\alpha \delta_{k} z_{j} \\
\Delta w_{0 k}=\alpha \delta_{k}
\end{gathered}
$$


h. Setelah itu pada setiap unit di lapisan tersembunyi dari unit ke-1 sampai unit ke-p dilakukan perhitungan informasi kesalahan lapisan tersembunyi $\delta_{j} . \delta_{j}$ kemudian digunakan untuk menghitung besar koreksi bobot dan bias antara lapisan input dan lapisan tersembunyi.

$$
\begin{gathered}
\delta_{j}=\left(\sum \delta_{k} w_{j k}\right)_{k=1}^{m} f^{\prime}\left(v_{0 k}+\sum x_{i} v_{i j}\right)_{i=1}^{n} \\
\Delta v_{i j}=\alpha \delta_{j} x_{i} \\
\Delta v_{0 j}=\alpha \delta_{j}
\end{gathered}
$$

i. Tahap selanjutnya yaitu meng-update bobot dan bias, setiap unit output $y_{k}$ dari unit ke-1 sampai unit ke-m dilakukan pengupdatean bias dan bobot sehingga bias dan bobot mempunyai rumus seperti :

$$
w_{j k}(\text { baru })=w_{j k}(\operatorname{lama})+\Delta w_{j k}
$$

Dari unit ke-1 sampai unit ke-p di lapisan tersembunyi juga dilakukan pembaharuan bias dan bobotnya yang mempunyai rumus seperti berikut:

$$
v_{i j}(\text { baru })=v_{i j}(\operatorname{lama})+\Delta w_{i j}
$$

\section{Hasil dan Pembahasan}

\begin{tabular}{|c|c|c|c|c|}
\hline Nama & MSE Epoch Pertama & MSE Epoch Terakhir & Jumlah Iterasi & Akurasi \\
\hline Batu Ruby & 0,10113 & 0,0978512 & 100 iterasi & $86,08 \%$ \\
\hline Batu Ruby Sintetis & 0,2257 & 0,1854 & 100 iterasi & $85,19 \%$ \\
\hline
\end{tabular}

Proses yang telah dilakukan mendapatkan nilai minimal, maksimal dan nilai akurasi dengan cara menentukan kebutuhan jaringan dengan maksimum epoch yaitu 100, target 0,01 dan learning rate 0,01.

Berikut hasil yang telah didapatkan:

Tabel 1. Hasil Epoch dan Akurasi.

Dalam hasil yang sudah didapatkan pada Tabel 1 bahwa implementasi pengenalan pola untuk identifikasi batu mulia menggunakan algoritma backpropagation mempunyai rata-rata nilai akurasi $85 \%$ tepat dalam pengenalan polanya.

\section{Kesimpulan}

Implementasi jaringan syaraf tiruan dengan menggunakan metode backpropagation pada identifikasi batu mulia yaitu mempunyai rata-rata akurasi sebesar $85 \%$ dalam mengidentifikasi batu mulia asli dengan batu sintetis, perlu dilakukan penelitian selanjutnya untuk mengidentifikasi sehingga keakurasian melebihi $85 \%$ bisa dengan menggunakan metode Hidden Markov Model atau pengenalan pattern yang lainnya.

\section{Daftar Pustaka}

[1] A. A. Kasim and A. Harjoko, "Klasifikasi Citra Batik Menggunakan Jaringan Syaraf Tiruan Berdasarkan Gray Level Co- Occurrence Matrices ( GLCM )," Semin. Nas. Apl. Teknol. Inf. Yogyakarta, 21 Juni 2014, pp. 7-13, 2014.

[2] A. H. Rangkuti, "Klasifikasi Motif Batik Berbasis Kemiripan Ciri Dengan Wavelet Transform Dan Fuzzy Neural Network," no. 9, pp. 361-372, 2013.

[3] B. Pengkajian, T. Pertanian, B. Besar, and P. Tanaman, "Identifikasi Varietas Berdasarkan Warna dan Tekstur Permukaan Beras Menggunakan Pengolahan Citra Digital dan Jaringan Syaraf Tiruan,” pp. 91-97, 2013.

[4] D. Amirullah, "Sistem Pencarian Semantik Impresi dengan Mekanisme Pembobotan Kombinasi Fitur Warna dan Fitur Bentuk," 2018.

[5] D. Puspitaningrum, "Pengantar Jaringan Syaraf Tiruan," 2014.

[6] D. Z. Herman, "Pendayagunaan mineral untuk menjadi permata," Museum Geol., vol. 5, no. 7, pp. 45,2008 .

[7] I. N. da Silva, D. Hernane Spatti, R. Andrade Flauzino, L. H. B. Liboni, and S. F. dos Reis Alves, Artificial Neural Networks. 2017. 
[8] M. H. Fauzi et al., "Implementasi Thresholding Citra Menggunakan Algoritma Hybrid Optimal Estimation," Teknol. Inf., 2010.

[9] P. Nuriskianti, K. Adi, J. Fisika, F. Sains, and U. Diponegoro, "Menggunakan Jaringan Syaraf Tiruan Propagasi Balik," vol. 4, no. 2, pp. 197-204, 2015.

[10] V. Pebrianasari, E. Mulyanto, and D. Erlin, "Analisis pengenalan motif batik Pekalongan," Techno.COM, vol. 14, no. 4, pp. 281-290, 2015. 